\title{
Adoção de Crianças por Casais Homossexuais: As Representações Sociais
}

\author{
José Victor De Oliveira Santos ${ }^{1, *}$ \\ Orcid.org/0000-0002-6661-2873 \\ Ludgleydson Fernandes de Araújo ${ }^{1}$ \\ Orcid.org/0000-0003-4486-7565 \\ Fauston Negreiros ${ }^{1}$ \\ Orcid.org/0000-0003-1116-6391 \\ Elder Cerqueira-Santos ${ }^{2}$ \\ Orcid.org/0000-0003-2046-8463
}

${ }^{1}$ Universidade Federal do Piauí, Parnaiba, PI, Brasil ${ }^{2}$ Universidade Federal do Sergipe, Aracaju, SE, Brasil

\section{Resumo}

A presente pesquisa objetivou identificar as representações sociais da adoção por casais homoafetivos na realidade brasileira. Participaram 589 adultos, de ambos os sexos, com idades entre 18 e 69 anos $(M=$ $27,43, D P=9,0)$ de diferentes regiões do país. Utilizaram-se entrevistas estruturadas e questionários sociodemográficos que foram analisados pelo software Iramuteq, que por sua vez apreendeu as representações sociais em classes de proximidade lexical. Os resultados apontaram, na Classificação Hierárquica Descendente, duas classes no corpus sobre adoção homoparental e cinco classes no corpus acerca do desenvolvimento infantil. Em sua maioria os resultados apontaram representações sociais positivas, sempre visando o melhor para o adotando como justificativa, por outro lado posicionamentos desfavoráveis encontrados refletem o receio da criança não conseguir lidar com o modelo familiar. Nesse sentido, acredita-se que as representações sociais acerca da adoção por casais homoafetivos documentadas neste estudo apontam conceitos que possam subsidiar medidas sociais que tragam ainda mais direitos para pessoas homossexuais.

Palavras-chave: Adoção, homoparentalidade, representações sociais, adultos brasileiros.

\section{Adoption of Children by Homosexual Couples: The Social Representations}

\begin{abstract}
This study aimed to identify the social representations of adoption by homosexual couples in the Brazilian reality. Participants where 589 adults of both genders, aged between 18 and 69 years $(M=27.43$, $S D=9.0$ ) from diverse backgrounds. Structured interviews and sociodemographic questionnaires were

* Endereço para correspondência: Universidade Federal do Piaú́, Departamento de Psicologia, Av. São Sebastião, 2819, Parnaíba, PI, Brasil 64202-020. E-mail: victorolintos@hotmail.com, ludgleydson@yahoo. com.br, faustonnegreiros@ufpi.edu.br e eldercerqueira@gmail.com Financiamento: Conselho Nacional de Desenvolvimento Científico e Tecnológico - CNPq.
\end{abstract}


used and were analyzed using the IRaMuTeQ software, which organized the social representations into classes of lexical proximity. Results showed, a Descending Hierarchical Classification, with two classes in the corpus of same-sex parent adoption and five classes in the corpus about childhood development. These mainly highlighted positive social representations, always seeking the best for the adoptee as the justification, however, unfavorable positions found reflected the fear that the child would not be able to cope with the family model. In this sense, it is believed that the social representations about adoption by homosexual couples documented in this study indicate concepts that could support social interventions that increase the civil rights of homosexual parents.

Keywords: Adoption, same-sex parenting, social representations, Brazilian adults.

\section{La Adopción de los Niños por Parejas Homosexuales: Las Representaciones Sociales}

\section{Resumen}

Esta investigación tuvo como objetivo identificar las representaciones sociales de la adopción por parejas homosexuales en la realidad brasileña. Participaron 589 adultos de ambos sexos, con edades entre 18 y 69 años $(M=27.43, D E=9.00)$ en diferentes regiones. Se utilizarón entrevistas estructuradas y cuestionarios sociodemográficos fueron analizados por el software Iramuteq, que se hizo con las representaciones sociales en las clases de proximidad léxicos. Los resultados mostraron, la clasificación jerárquica descendente, dos clases en el corpus de la adopción homoparental y cinco clases en el corpus sobre el desarrollo infantil, en su mayoría han demostrado las representaciones sociales positivas, buscando siempre la mejor para la adopción como justificación, sin embargo posiciones desfavorables encontradas reflejan el miedo del niño no puede manejar el modelo de familia. En este sentido, se cree que las representaciones sociales acerca de la adopción por parte de parejas homosexuales documentados en este studio indican conceptos que pueden apoyar medidas sociales todavía traen más derechos para las personas homosexuales.

Palabras clave: Adopción, homoparentalidad, representaciones sociales, adultos brasileños.

O modelo de família considerado padrão (pai, mãe e filhos), que teve seu auge no século $\mathrm{XX}$, age consoante a algumas mudanças sociais. Com o aumento de novas configurações de família o modelo nuclear/patriarcal vai dando espaço para outras formas de organização familiar, como as famílias monoparentais e homoparentais, por exemplo (Bergman, Rubio, Green, \& Padròn, 2010; Murphy, 2013). A constituição e manutenção da família dependem de laços afetivos e não necessariamente do casamento judicial e/ou religioso, de tal forma que os princípios de reprodução e complementaridade entre os sexos passam a ser secundários; e a filiação passa a ser embasada em outros modos, nas formas de companheirismo e afetividade (DelaCruz \& Uziel, 2014).

As autoras Dias e Reinheimer (2013) enfatizam que com o avanço das conquistas legais no plano dos direitos humanos, o conceito de família não está associado à celebração do matrimônio. Em virtude disto, o reconhecimento da homoparentalidade, por parte da população, comprova que as famílias formadas por casais homossexuais estão próximas de deter os direitos que qualquer outro modelo familiar deve possuir. Nesse contexto, sabe-se que o número de pessoas que se autodeclaram homossexuais está em expansão e como consequência a isto, o surgimento de famílias homoparentais se torna mais frequente. Assim o Brasil possui cerca de 60 mil casais homossexuais, uma quantidade significativamente pequena diante do contingente nacional que se autodeclara homossexual, sendo respectivamente, 17 milhões de pessoas (Instituto Brasileiro de Geografia e Estatística [IBGE], 2011).

Desde a década de 1990, as lutas pelos direitos de homossexuais têm se intensificado, em busca principalmente de reconhecimento 
da conjugalidade por pares do mesmo sexo, possibilidades de adoção e combate à homofobia (Uziel, 2007). Os direitos dos homossexuais não devem apenas ficar à espera de serem aceitos juridicamente, é necessário consolidar estes avanços, uma vez que a consagração de tais direitos pode ser uma forma conveniente de reduzir as manifestações de preconceito (Dias \& Reinheimer, 2013).

O Conselho Nacional de Justiça (CNJ) através da resolução $\mathrm{n}^{\circ} 175$, de 14 de maio de 2013 , estabeleceu que fossem vedadas às autoridades do direito a recusa de habilitação, celebração de casamento civil e substituição de regime em união estável em casamento entre pessoas do mesmo sexo. Tal resolução assegura direitos antes possíveis apenas aos casais heterossexuais, a saber: igualdade nos direitos e deveres dos conjugues, separação com comunhão de bens, direito a pensão alimentícia e herança, entre outros.

A adoção homoparental é entendida como a modalidade de adoção na qual o casal adotante é constituído por homossexuais (Patterson, 2006) ou por apenas um indivíduo que se declara homossexual. A denominação homoparentalidade foi elaborada em 1996 na França, pela iniciativa da Associação dos Pais e Futuros Pais Gays e Lésbicos (Zambrano, 2006). Contudo, mesmo passadas duas décadas de que esse termo foi empregado pela primeira vez, ainda visualiza-se uma resistência em considerar a legitimidade aos casais homossexuais e seus filhos como família.

O Estatuto da Criança e do Adolescente (Lei $\left.\mathrm{N}^{\circ} 8.069,2014\right)$ expõe que para adoção conjunta, é necessário que os adotantes sejam casados civilmente ou tenham união estável, comprovando a estabilidade familiar, e para a adoção ser deferida basta apresentar reais benefícios para o adotando. Em nenhum termo cita que é possível adoção homoparental, porém, também não proíbe, sendo assim, a orientação sexual não deve ser critério de exclusão ou hierarquização de candidatos à adoção. Conforme analisam Cerqueira-Santos e Santana (2015), não há vedação legal para a instituição da adoção de crianças por casais homossexuais no país.
Nesse contexto, em março de 2015, a Ministra Carmem Lúcia, do Supremo Tribunal Federal, concedeu o direito de adoção a um casal homossexual pela primeira vez no Brasil (Foster, 2015 apud Fiuza, 2015). Todavia, apesar da conquista desses direitos, o que ocasiona maior visibilidade e situações positivas frente ao tema, seria ilusão afirmar que as manifestações de preconceito estejam ocorrendo em menor proporção, no país (Freires, 2015). Esse preconceito poderia ser comparado ao dedicado à lei do divórcio de 1970, que na época era encarado com escárnio e atualmente se tornou algo comum, induzindo a noção de que a sociedade leva determinado tempo para internalizar algum acontecimento (Uziel, 2007).

Com relação às formas de parentalidade, Grossi (2003) afirma que a literatura científica destaca quatro formas de filiação homoparental: (a) Ter filhos em relações heterossexuais anteriores a assumir-se homossexual; (b) Adoção por um dos parceiros, sendo o representante legal da criança; (c) Procriação com terceiro indivíduo fora da relação de conjugalidade, através de novas tecnologias reprodutivas e, por fim, (d) A coparentalidade entre gays e lésbicas. Salienta-se que o CNJ (2015) já permite a inserção dos casais homossexuais no cadastro nacional de adoção, de modo que seria o quinto modelo de filiação, e importante conquista nos direitos civis das famílias homossexuais.

O desafio de encontrar uma forma cabível de ter um filho se torna angustiante, a impossibilidade de gerar prole exige um trabalho psíquico, envolvendo a decisão de abandonar o princípio narcísico de continuidade biológica e aceitação de agentes externos para a concepção da criança (Passos, 2005). Essa autora ainda enfatiza que as dificuldades de concepção de um filho, inúmeras vezes, ocasiona a desistência do desejo de projetar um filho.

$\mathrm{Na}$ circunstância da formação de uma família homoparental e da adoção, faz-se mister considerar as demandas das crianças e dos adotantes que são os atores sociais implicados neste processo psicossocial (Almeida, 2008). Assim, é importante pontuar que o discurso do senso co- 
mum - geralmente fundamentado nas suas concepções religiosas - serve de base para formas de expressões do preconceito às pessoas homossexuais, demonstrando formas de repúdio ao casamento e à adoção, atitudes que podem ser entendidas através das representações sociais acerca dos homossexuais (Pereira, Torres, Falcão, \& Pereira, 2013).

Apesar da autorização da adoção homoparental, o não reconhecimento da população reflete em atitudes preconceituosas, possivelmente, pelo fato do estado não fornecer o devido amparo legal a esta causa, isto é, existem legislações mas nas articulações práticas, não são executadas adequadamente (Cerqueira-Santos \& Santana, 2015; Silva \& Silveira, 2015). Nesta direção, percebe-se que é deixada de lado a felicidade de um casal que busca adoção e a oportunidade de inserção de uma criança numa família, para atender a noções que foram fixadas na sociedade, mas que precisam ser reconsideradas. A inacessibilidade de informações científicas sobre o assunto é um subsídio que conduz opiniões enviesadas sobre a homoparentalidade, o que torna o tema um desafio social e educativo de conscientização (Gato \& Fontaine, 2010).

Em uma pesquisa de revisão sistemática da literatura, Cecílio, Scorsolini-Comin, e Santos (2013) apontam que no Brasil, em uma década (2000-2010) apenas dez estudos sobre a adoção homoparental foram realizados e publicados nas principais bases de dados científicas do país. Dentre eles, três artigos empíricos e sete teóricos. Os autores destacam especialmente três tendências nos estudos sobre a temática: a preocupação com as consequências da adoção para as crianças (aspectos desenvolvimentais negativos e positivos); as alternativas na busca da parentalidade; e as questões ligadas à adoção em si (legislação, mudanças históricas e outros).

Em um estudo prévio verificou-se que os entrevistados acreditam que a adoção homoparental é uma solução mais viável se comparada a possibilidade de as crianças crescerem em instituições de abrigo, sendo uma excelente opção para a falta de opção (Silva \& Uziel, 2011). Nessa concepção, portanto, vigora o discurso do mal menor (Uziel, 2007), ou seja, é um mal menor o desenvolvimento da criança ocorrer numa família homoparental, diante da possibilidade de criar-se em um abrigo.

Uma pesquisa realizada em Portugal, que buscou analisar a opinião de universitários com relação à homoparentalidade, obteve um resultado equivalente a $66 \%$ dos sujeitos contra a igualdade de direitos no exercício da parentalidade (Xavier, Mendes, Martins, \& Fernandes, 2011). Em outro trabalho executado com universitários brasileiros na perspectiva das representações sociais, obteve-se que $51 \%$ dos participantes são contra a adoção por casais homossexuais, esse resultado pode ser indicado pela representação de que o fato acarretaria um desenvolvimento inadequado e a criança poderia seguir a orientação sexual dos pais (Araújo, Oliveira, Sousa, \& Castanha, 2007). Assim, dados consonantes as investigações dos autores supracitados foram demonstrados entre universitários de Direito e Serviço Social (Cerqueira-Santos \& Santana, 2015). Tais discursos estão embasados em estereótipos e atitudes negativas sobre o tema, uma vez que não existe qualquer indicio científico comprovado sobre o fato de que a homoparentalidade seja prejudicial ao adotando (Silva \& Uziel, 2011).

Em um trabalho recente, Freires (2015) disserta sobre as atitudes frente à homoparentalidade, a partir de cinco estudos. No geral buscou mapear a opinião dos participantes a respeito da adoção homoparental. Como resultado, observou-se o discurso de aceitação desde que haja um ambiente favorável ao desenvolvimento da criança. A preocupação implícita em relação ao desenvolvimento da criança acaba gerando opiniões preconceituosas devido à preocupação sobre a influência dos papéis sociais de gênero. Neste sentido, fazem-se necessárias investigações científicas com o escopo de verificar os conhecimentos elaborados e compartilhados (as representações sociais) pelos grupos sociais acerca da adoção por casais homossexuais.

Numa perspectiva da Psicologia Social, a Teoria das Representações Sociais, propicia uma visão ampliada a respeito das crenças, conceitos 
e explicações que as pessoas manifestam através do senso comum (Moscovici, 2003). Assim, as representações sociais são formas de conhecimentos popularmente elaborados, ancorados e compartilhados, construindo conceitos para a realidade de um grupo social (Jodelet, 2001). Elas surgem como ferramenta para analisar as conviç̧ões da realidade, advindos da aquisição de novos pensamentos e questionamentos no seio da ciência (Arruda, 2002).

No contexto da adoção homoparental, as representações sociais circundam o conjunto de opiniões, atitudes e reações sobre esse fenômeno, que perpassa os construtos sociais e pessoais do sujeito. Tais fatores são responsáveis por produzir respostas negativas ou positivas, criando crenças de preconceito e intolerância ou aceitação (Araújo \& Oliveira, 2008).

Diante do exposto, o presente artigo tem como escopo, analisar como as pessoas adultas de diversas regiões brasileiras representam a adoção por casais homossexuais, tendo como pressuposto teórico as representações sociais, que envolvem os aspectos sociais e cognitivos, o que possibilita interpretar os conceitos socialmente elaborados, com a intenção de aprofundar e enriquecer as discussões a respeito do tema.

\section{Método}

\section{Tipo da Investigação}

Trata-se de uma pesquisa ex post facto utilizando dados transversais.

\section{Participantes}

A amostra foi composta por 589 adultos, de ambos os sexos, com idades entre 18 e 69 anos $(M=27,43, D P=9,0)$ de diferentes regiões brasileiras. As mulheres compuseram a maior parte da amostra do estudo (60,3\%). Destes, $71,1 \%$ são solteiros, $19,7 \%$ casados, e o restante da amostra é composta por união estável $(6,3 \%)$, divorciados ou separados $(2,8 \%)$ e viúvos $(0,1 \%)$. No que se diz respeito à escolaridade, $50,5 \%$ dos participantes, estão cursando ensino superior, 23,9\% são pós-graduados e $15,9 \%$ tem ensino superior, ensino médio e fundamental atingiram $9,8 \%$ da amostra. Quanto à orientação sexual $84,2 \%$ dos participantes são heterossexuais e 11,6\% são homossexuais ou bissexuais. Em relação à religião, $35,7 \%$ são católicos, alguns acreditam em Deus, mas não seguem nenhuma religião $(24,5 \%)$, católicos não praticantes (11,6\%), evangélicos $(10,2 \%)$, espíritas $(6,0 \%)$, os demais identificam-se como ateus, testemunhas de Jeová, budistas, candomblé e umbanda. De acordo com o posicionamento político, $36,7 \%$ se declaram de esquerda, $25,5 \%$ de centro-esquerda, $14,8 \%$ de centro-direita e de direita (23,0\%).

\section{Instrumentos}

No que diz respeito aos instrumentos utilizou-se inicialmente, um questionário sociodemográfico com o intuito de realizar uma caracterização da amostra, composto por perguntas relativas a: idade, sexo, estado civil, religiosidade ou espiritualidade, orientação sexual, grau de escolaridade. Em seguida, foram empregadas duas perguntas, baseadas em estudos prévios (Araújo \& Oliveira, 2008; Araújo et al., 2007; Freires, 2015). As respectivas perguntas abordam as representações sociais da adoção e do desenvolvimento infantil no contexto homoparental. A primeira, "Qual a sua opinião sobre a adoção de crianças por casais homossexuais?" A segunda, "Qual a sua opinião sobre o desenvolvimento infantil de uma criança adotada por um casal homossexual?".

\section{Procedimentos Éticos}

O presente projeto de pesquisa foi aprovado pelo Comitê de Ética em Pesquisa (CEP) da Universidade Federal do Piauí. Os dados foram coletados via formulário Google Docs (Online). A obtenção de participantes para a composição da amostra foi através das redes sociais e $e$ -mails. Na coleta de dados, foi esclarecido que a participação era de forma voluntária e anônima, explicitando os objetivos do estudo, a obtenção das devidas autorizações, bem como, o preenchimento dos Termos de Consentimento Livres e Esclarecidos, de acordo com o disposto na Resolução 466/12 do Conselho Nacional de Saúde (CNS), para que os participantes pudessem autorizar sua participação na pesquisa e responder aos instrumentos. É válido salientar que foram 
garantidos todo sigilo e confidencialidade das respostas dos participantes e que a desistência poderia ocorrer a qualquer momento. $\mathrm{O}$ tempo necessário de participação foi em torno de 30 minutos.

\section{Procedimento de Análise dos Dados}

Para análise dos dados, utilizou-se o software IRAMUTEQ - Interface de R Pour Analyses Multidimensionnelles de Textes et de Questionnaires (Camargo \& Justo, 2013; Nascimento \& Menandro, 2006; Ratinaud, 2009), que é compilado a partir do software $\mathrm{R}(R$ Development Core Team, 2011), responsável por analisar os dois corpus textuais atribuídos as duas perguntas respondidas pelos participantes que compõem a amostra, tais corpus foram estruturados no editor de texto OpenOffice Writer, compostos por 600 Unidades de Contextos Iniciais (UCIs). As análises descritivas foram feitas a partir do software IBM SPSS Statistic 21.

Nas análises, realizou-se o procedimento de Classificação Hierárquica Descendente (CHD), que é apresentada no formato de árvore, o dendograma. $\mathrm{O}$ que indica as classes lexicais em que foi dividido o discurso, a partir da frequência e do qui-quadrado $\left(X^{2}\right)$, modelo este, que foi proposto por Reinert (1990).

\section{Resultados}

No que concerne à pergunta a respeito das representações sociais da adoção por casais homossexuais, que compõe o corpus 1 , foram encontrados diversos posicionamentos, porém na sua maioria, se mostraram favoráveis a adoção. O mesmo foi formado por 589 UCIs e 672 Unidades de Contexto Elementar (UCEs), possuindo um total de ocorrências equivalentes a 13.753 , que podem ser palavras, ou vocábulos distintos. A partir da análise de classificação hierárquica descendente (CHD), em que foram divididas em duas classes lexicais, documentando-se apenas aquelas que o qui-quadrado perpassou o valor de $X^{2} \geq 12,52$.

No dendograma 1 , registra-se as duas classes, que puderam ser denominadas como "con- cepção assertiva" e "concepção parcialmente adepta", correspondendo, respectivamente as classes 1 e 2. São indicadas, as UCEs por classe, a variável descritiva que representa a amostra, a frequência média de cada palavra e o valor do qui-quadrado. A classe 1, como pode ser observado na Figura 1, foi representada por $79,15 \%$ das UCEs. Quanto as variáveis descritivas, pessoas bissexuais e/ou espíritas apresentam discursos que mais coincidem com o obtido na classe 1 e pessoas heterossexuais na classe 2. Ressalta-se que o uso das variáveis descritivas significa que as representações sociais daquele perfil foi a que mais corroborou o tipo classe representacional, mas não significa que foi formada apenas pelas variáveis descritivas explicitadas no dendograma. É notório que a classe 1 representa, sobremaneira, a maior parte da amostra, ou seja, ela possui mais relevância semântica.

tões que envolvem o amor recíproco entre criança e casal adotante. Como pode ser observado na Figura 1, evidencia-se que a assertividade é presente, podendo inferir representações vinculadas ao amor que o casal vai conceder para a criança, sendo este o fator mais importante para o desenvolvimento do adotando. Tais representações podem ser percebidas no discurso de alguns participantes, como o participante 064 , 22 anos, que acredita em Deus, mas não segue nenhuma religião, heterossexual e cursa o ensino superior, que diz "Trata-se de algo normal, tendo em vista que o que importa é o amor, carinho e educação que serão oferecidos à criança".

A questão do cuidado, amor e bem-estar da criança como fator primordial para a adoção passam a ser ancorados também no contexto homoparental, discernir a capacidade de um casal adotar a partir da sua sexualidade, é algo totalmente errôneo, como pode ser evidenciado nesta fala: "Não vejo qualquer impedimento, a adoção deve servir à criança, oferecendo-lhe uma familia capaz de amar e de cuidar, e para tanto, pouco importa a orientação sexual do casal" (Participante 405, 21 anos, ensino superior incompleto, mulher, heterossexual, acredita em Deus, mas não tem religião). 


\begin{tabular}{|c|c|c|c|c|c|}
\hline \multicolumn{3}{|c|}{$\begin{array}{c}\text { Classe 1 } \\
467 \text { UCEs = 79,15\% } \\
\text { variáveis descritivas: } \\
\text { Espiritas e bissexuais } \\
\text { Concepção } \\
\text { assertiva }\end{array}$} & \multicolumn{3}{|c|}{$\begin{array}{c}\text { Classe 2 } \\
123 \text { UCEs }=20,85 \% \\
\text { variáveis descritivas: } \\
\text { Heterossexuais } \\
\text { Concepção } \\
\text { parcialmente } \\
\text { adepta }\end{array}$} \\
\hline Palavras & f & $X^{2}$ & Palavras & f & $X^{2}$ \\
\hline Criança & 280 & 40,54 & Mulher & 14 & 54,45 \\
\hline Amor & 142 & 36,84 & Homem & 14 & 54,45 \\
\hline \multirow[t]{11}{*}{ Casal } & 219 & 24,63 & Ainda & 17 & 40,13 \\
\hline & & & Aceitar & 12 & 37,23 \\
\hline & & & Natural & 17 & 26,25 \\
\hline & & & Muito & 40 & 26,05 \\
\hline & & & Assunto & 08 & 21,83 \\
\hline & & & Formado & 10 & 21,57 \\
\hline & & & Diferente & 09 & 17,95 \\
\hline & & & Concordar & 22 & 15,73 \\
\hline & & & Realidade & 04 & 15,29 \\
\hline & & & Lei & 04 & 1529 \\
\hline & & & Homossexualidade & 04 & 15,29 \\
\hline
\end{tabular}

Figura 1. Dendograma 1, distribuição das classes nas Representações Sociais da adoção homoparental.

A Classe 2, foi composta por 123 UCEs equivalente a $20,85 \%$ do total, este, que é observado uma maior variedade de vocábulos, perfazendo representações sociais ancoradas em concepções parcialmente adeptas à adoção, que por um lado, aceitam a adoção desde que existam as condições dignas para o desenvolvimento do adotando, mas por outro, encontra-se indivíduos com posicionamentos desfavoráveis.

Como foi demonstrado na Classe 2 (ver Figura 1) as palavras que mais representam esta classe são mulher e homem, estes, que foram utilizados como meio de comparação em relação aos casais homossexuais, que por sua vez, justificavam que eram adeptos a adoção por considerar natural, mas diferente, pois existem muitos conceitos formados sobre o tema, que por sua vez, estão repletos de estigmas associados à pessoa homossexual.
Esta fala, exemplifica um dos pontos de vista que compõe a classe 2: "Aceitável, crianças precisam de um lar. E um casal homossexual se dedicaria aos seus filhos adotivos tanto quanto um casal heterossexual" (Participante 034, 18 anos, ensino superior incompleto, mulher, heterossexual, católica). Alguns discursos encontrados apresentam a constante questão comparativa, em que se busca explicar a normalidade da adoção homoparental, comparando com exemplos heterossexuais, como pode ser observado: "Todo casal que possua capacidade financeira e psicológica para se responsabilizar por uma criança é apto a adotar, sendo ele homossexual ou heterossexual" (Participante 047, 23 anos, ensino superior incompleto, homem, bissexual, católico não praticante). $\mathrm{O}$ que infere a aceitação desde que os pais sejam pessoas ajustadas e estruturadas financeiramente na sociedade. 
Encontram-se representações sociais que deslocam o preconceito para a sociedade, ou seja, é a favor, mas acha que não seria adequado, pois a sociedade é preconceituosa e acredita que o bullying será vivenciado constantemente na vida das crianças, tornando-as pessoas com problemas psicológicos. Nesse sentido, o presente discurso caracteriza, parcialmente, algumas representações identificadas na amostra, " $A$ adoção é igual, eu não tenho preconceito com isso, mas a sociedade em geral é muito opressora" (Participante 234, 32 anos, ensino médio, mulher, heterossexual, evangélica).

A Classificação Hierárquica Descendente (CHD), que corresponde as representações sociais acerca do desenvolvimento infantil no contexto homoparental, que formam o corpus 2 foi composto por 576 UCIs e 651 UCEs, apre- sentando uma ocorrência de 13.175. O corpus 2 foi dividido em cinco classes de segmentos de texto, e buscou-se descrever as palavras em que o valor do qui-quadrado fosse $X^{2} \geq 15,13$. Como pode ser observado na Figura 2, o dendograma apresenta três campos representacionais, um deles, correspondendo as classes 1 e 2, o outro, as classes 3 e 4, e por fim o terceiro campo formado pela classe 5. É notável, que os dois primeiros campos representacionais, apresentam oposição entre si, como o composto pelas classes 1 e 2, que ficaram denominadas, respectivamente, "desenvolvimento saudável" e "desenvolvimento inadequado", e as classes 3 e 4, foram intituladas de "sociedade preconceituosa" e "adoção igualitária". A classe 5, ficou num único segmento de texto, foi denominada "normalidade total".

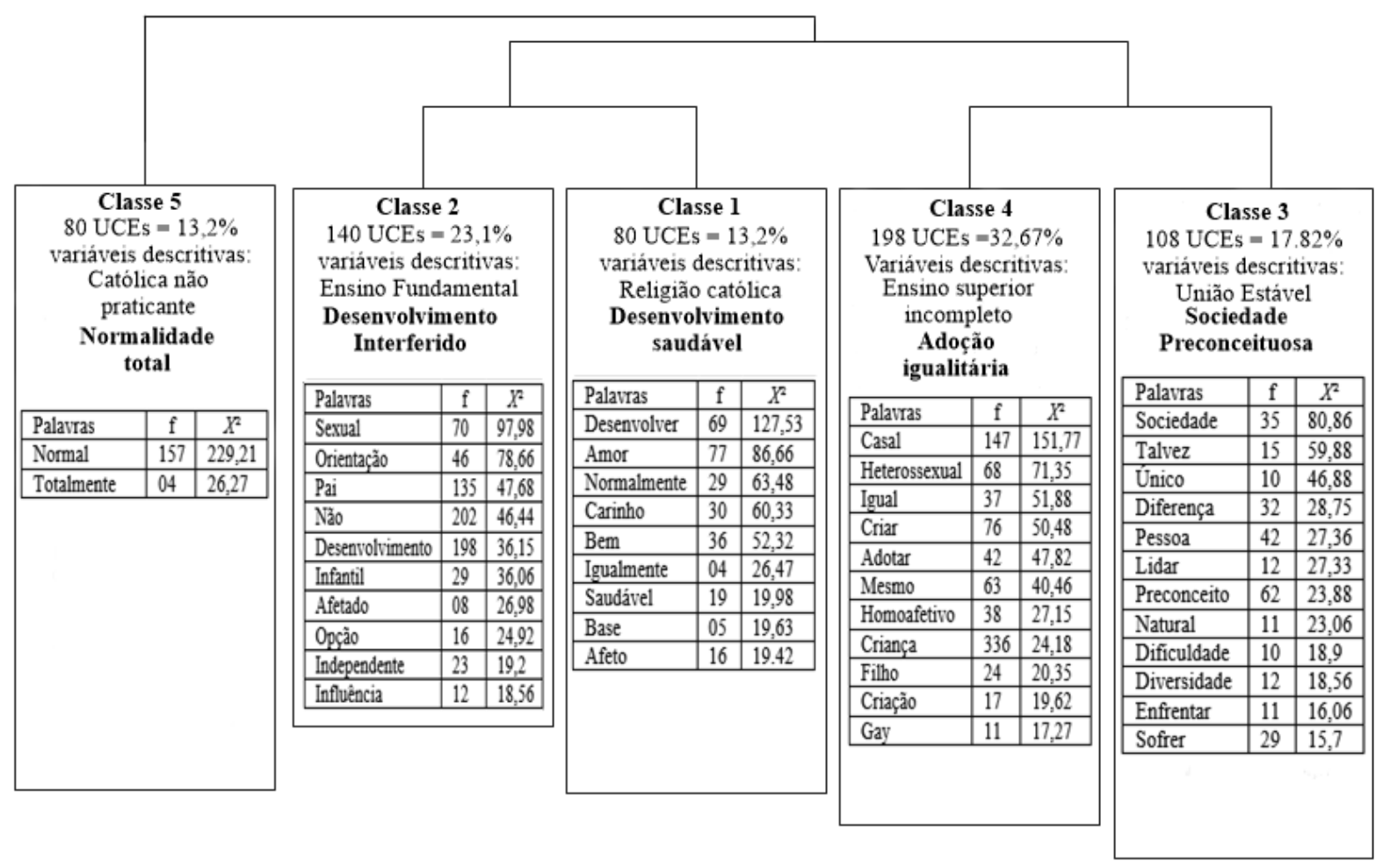

Figura 2. Dendograma 2, distribuição das classes nas Representações Sociais do desenvolvimento infantil no contexto homoparental.

A Classe 1, foi composta por 140 UCEs, $23,1 \%$ do total, em que a variável descritiva mais relevante, foi a religião católica. No dendograma da Figura 2, é possível observar que os vocábulos referentes às representações pertinentes ao desenvolvimento infantil, apontam que o desen- volvimento será normal, pois havendo uma relação de amor e carinho, este, tenderá a ser saudável. O seguinte discurso levanta os aspectos gerais que compõem esta classe:

O desenvolvimento infantil de uma criança é saudável se a mesma receber amor, aten- 
ção, afeto, cuidado, carinho, seja de pais heterossexuais ou não. Um casal homossexual trará sim um bom desenvolvimento para uma criança, independentemente de sua escolha sexual, pois o que importa para um desenvolvimento saudável está além da sexualidade dos pais. (Participante 127, 19 anos, ensino superior incompleto, bissexual, agnóstica)

A classe 1 aponta ainda, que o desenvolvimento deve ser igual, tendo em vista que é necessária uma base familiar, independentemente da orientação sexual dos pais. A Classe 2 obteve 140 UCEs, sendo $23,1 \%$ do total, em que a variável descritiva que se destacou foi ensino fundamental. Esta classe demonstrou certo ponto de oposição em relação à Classe 1, apontando termos que objetivam as representações sociais do desenvolvimento como possível influência da orientação sexual dos pais, porém, ainda exploram o sentido de ser uma boa opção independentemente da orientação dos pais.

A palavra "não", como pode ser observada, está associada a palavras negativas, no sentido de não concordar, ver problema nisso, não achar certo, que foi presente principalmente nos discursos dos evangélicos brasileiros. Porém, podem-se observar posicionamentos a partir do não, mas demonstram favorabilidade, ou seja, representações que ancoram suas crenças no "não vejo problema nenhum" ou "não devemos inferir nisso". Esse discurso pode ser observado na fala da participante 320,21 anos, católica e ensino superior incompleto, heterossexual, que diz "Acredito que a criança se desenvolverá normalmente, não acredito em nenhum dano psíquico ou físico para ela".

A Classe 3 denominou 108 UCEs, referindo a $17,82 \%$ do total, a variável descritiva que prevaleceu foi união estável. Esta classe ficou denominada como "sociedade preconceituosa", o que por um lado indica vocábulos negativos que evidenciam que a criança irá sofrer preconceito e terá dificuldade com isso, mas por outra ótica, constrói um conceito relacionado à diferença que se pode lidar e enfrentar, pois a diversidade na sociedade existe, ou seja, há preconceito, mas isso não significa que a criança irá absorver isto e crescer carregando traumas. A participante 316, com 19 anos, que tinha o ensino superior incompleto, heterossexual, católica não participante dialoga de forma concisa e explica basicamente as representações sociais desta classe: "Será um desenvolvimento com algumas dificuldades por conta do preconceito das pessoas, mas sabendo lidar com essas dificuldades será um desenvolvimento normal como de outras crianças".

A Classe 4, que compôs a maioria das UCEs, perfaz um total de 198, ou 32,67\% que assinala o sentido de adoção igualitária, ressaltando que casal heterossexual ou homossexual irá fornecer os subsídios necessários para a criação. Quanto à variável descritiva mais evidente, pessoas que estão cursando o ensino superior foram as que mais demonstraram representações sociais de acordo com a classe. Constata-se a brilhante forma de explicar suas opiniões, que ancoram sua crença em algo que conhece e objetiva a um sentido semelhante, surgindo assim, as representações sociais, e nesta classe, a atribuição a adoção como um fator igualitário, demonstra que as pessoas tendem a se embasar no conceito comum para ter um posicionamento sobre o tema novo que surge na sociedade.

Nesse contexto, a seguinte sentença aborda claramente o tipo de representações sociais que fundamenta a classe 4 (ver Figura 2). Como pode ser exemplificado na fala a seguir:

Uma criança filha de um casal homossexual tem as mesmas condições de uma criança filha de heterossexuais. Essa história de que criança adotada por homossexual vai crescer e ser influenciada pelos pais a virar homossexual não tem muito fundamento, se fosse verdade, filhos de casais heterossexuais seriam influenciados pelos pais a serem heterossexuais, e dessa maneira, homossexuais nunca teriam existido. (Participante 396, 19 anos, ensino superior incompleto, genderqueer)

No que diz respeito ao contexto de adoção igualitária, a classe 5 , que obteve 80 UCEs, $13,2 \%$ do total, apresentou a variável descritiva mais significativa, sendo os católicos não praticantes. Essa Classe apresentou apenas duas 
palavras, com valor suficiente para ser relevante, evidenciando o desenvolvimento infantil no contexto homoparental como totalmente normal.

No conjunto de dados desta investigação, pode-se observar que foram encontrados dois corpus textuais relacionados às representações sociais da adoção e do desenvolvimento infantil. Tais resultados são relevantes na medida em que se permite compreender os direitos conquistados pelos homossexuais, partindo dos conceitos socialmente elaborados que ancoram justificativas em preceitos positivos, associando a adoção e o desenvolvimento infantil como igual em qualquer contexto, no qual faz-se necessário que os adotantes disponibilizem subsídios psicossociais que tornem os filhos conscientes das qualificações e habilidades sociais fundamentais para o convívio na sociedade brasileira, dando educação e autonomia para um desenvolvimento saudável.

\section{Discussão}

A partir dos dados apreendidos entre os adultos brasileiros sobre as representações sociais da adoção e do desenvolvimento infantil no contexto homoparental, foram observados posicionamentos favoráveis, que aceitam a legitimação desse direito, posto que a adoção é uma forma de promover a felicidade das crianças e casais que buscam constituir uma família.

Salienta-se que a nova lei da adoção, $\mathrm{n}^{0}$ $12.010 / 2009$, e como parte da população se mostrando adepta, é sabido que há entre os casais homossexuais um receio em adotar, posto que ainda existem barreiras psicossociais e institucionais inerentes ao processo de adoção na família homoparental na vida em sociedade (Baiocco \& Laghi, 2013).

A partir de pesquisas que apreendem as representações sociais, atitudes e opiniões, é que se fundamenta a necessidade de dar amparo legal para sua efetiva existência na sociedade brasileira, e estas pesquisas relatam a necessidade do reconhecimento dos estabelecimentos em que toda família precisa usufruir para o desenvolvimento infantil e social da criança (Araújo \& Oliveira, 2008).
As pessoas levam um certo tempo para conceber novas representações, mas a incidência de debates que cabem às pessoas homossexuais, tem contribuído para representações positivas sobre a adoção homoparental. O que pode ser percebido em pesquisas realizadas previamente e demonstraram que os posicionamentos negativos, sobressaiam aos positivos (Araújo et al., 2007; Cerqueira-Santos \& Santana, 2015; Pacilli, Taurino, Jost, \& van der Toorn, 2011).

No que concerne à diferenciação entre gays e lésbicas, nota-se uma maior aceitação se for um casal formado por duas mulheres, por possuírem crenças relacionadas ao suposto instinto materno de criação (Costa et al., 2013). Pensamentos baseados na heteronormatividade demonstram rejeição que correlaciona o preconceito contra homossexuais ao preconceito em relação à parentalidade entre pais do mesmo sexo (Frias-Navarro, Monterde-i-Bort, Barrientos-Delgado, Badenes-Ribera, \& Cardenas-Castro, 2014).

As pessoas bissexuais por se enquadrarem no público LGBT, possuem maior probabilidade em aceitar o ato da adoção homoparental (Freires, 2015); assim como os praticantes da religião espírita, já que a literatura documenta que os mesmos possuem uma espiritualidade aberta a assuntos emergentes na sociedade (Dias, 2011). Os heterossexuais, nos seus discursos, abordam as questões de verificar se o casal homossexual possui condições seguras de adotar (Costa et al., 2013), neste sentido, que este estudo demonstrou, que as pessoas bissexuais e espíritas eram as que possuíam as representações sociais mais adeptas a adoção homoparental, e as pessoas heterossexuais, parcialmente adeptas.

Por outro lado, estudos prévios identificaram que as atitudes negativas estão sendo desconstruídas e perdendo espaço para crenças que contemplam o contexto de aceitação, as quais expressam o desejo de reduzir as disparidades sociais e implementar medidas públicas que marquem um novo momento, o de igualdade (Baiocco, Argalia, \& Laghi, 2014; Freires, 2015). Como apontam Cecílio et al. (2013), a visibilidade das famílias homoparentais como um contexto possível e não-tradicional tem forçado 
que se pense as relações de parentesco de diferentes perspectivas.

Nesse contexto, as pressões anti-preconceito, que estão presentes na sociedade, têm um papel fundamental na redução dos estigmas e tabus, mas que por sua vez, tem diminuído as manifestações relacionadas ao preconceito flagrante e ao sutil (Pereira, Monteiro, \& Camino, 2009). A discriminação por conta do gênero e orientação sexual ainda existe, porém a redução do níveis de preconceito através da compreensão acerca das questões de gênero pode levar a posicionamentos mais assertivos.

Em síntese, os resultados desta pesquisa assinalam que deve ser concedido o direito de adoção para pares homossexuais, devido ao fato da maioria da amostra demonstrar representações sociais favoráveis. Partindo do pressuposto de que o necessário para uma adoção segura é a responsabilidade, afetividade e dedicação, como apresentou-se nos resultados do presente estudo, certamente, é o subsídio necessário para um desenvolvimento psicossocial adequado que favoreça a integração da criança na família e na sociedade.

As famílias homoparentais trazem para a sociedade a possibilidade de reinventar essas relações de parentesco (Cerqueira-Santos \& Santana, 2015). A interpretação constitucional ocorre através de argumentos públicos e não por concepções estigmatizantes e reduzidas ao moralismo e dogmas religiosos (Barroso, 2011). Denota-se a necessidade de políticas públicas com escopo de diminuir a intolerância, estigma social e preconceitos frente à constituição de famílias homoparentais na realidade do país.

Mesmo que a Constituição Federal de 1988 aborde o princípio de igualdade, a necessidade de uma legislação clara e precisa sobre os direitos homossexuais seria então a maior possibilidade de liberdade, igualdade, dignidade e segurança para a população LGBT (Barroso, 2011; Dias \& Reinheimer, 2013). Destarte, não só as legislações apontam que o amparo legal deve ser consolidado, mas também a produção científica embasa que o desenvolvimento infantil em famílias homoparentais não causam danos biopsi- cossociais a criança e/ou adolescente (Baiocco et al., 2014; Cerqueira-Santos \& Santana. 2015; Freires, 2015; Patterson, 2006). Um processo árduo de adoção, dificulta a efetivação desta, mas a persistência dos casais LGBT, faz com que haja inúmeros casos consolidados positivamente (Machin, 2016).

A partir de mudanças individuais surgem mudanças institucionais, dia após dia, os sujeitos buscam compreender novos assuntos e passam a reduzir os estigmas relacionados às pessoas homossexuais (Costa et al., 2013). Devido a isso, o Brasil já consolidou alguns direitos, e consequentemente, caminha em busca de outros, cuja consumação irá perfazer um país mais adepto, inclusivo e assertivo em relação a diversidade sexual e seus direitos.

Nesse contexto, nota-se que os resultados apresentaram complexos campos representacionais que embasam o sentido de mudança que a sociedade vem passando. Subjacente a isso, os dados empíricos aqui obtidos deviam designar medidas a serem acatadas por instituições que explanem o progresso de tais assuntos, que do senso comum, tornam-se científicos. Através destas esferas de representações sociais, ao longo deste artigo, observou-se a relevância do tema, que está no auge de discussões. Ademais, sua pertinência é indispensável para embasar posicionamentos com visão fundamentada em pesquisas científicas e jurisprudência.

\section{Considerações Finais}

Este estudo evidenciou as principais representações sociais sobre adoção por casais homossexuais que circundam o contexto nacional, podendo englobar os mais diversos tipos de participantes, incluindo diversos tipos de religião, posicionamento político, grau de instrução, orientação sexual, idade e outras variáveis que caracterizam a diversidade de cidadãos brasileiros. Então a contribuição deste trabalho para este fenômeno que instiga inúmeras discussões no país é substancial para indicar pensamentos assertivos que diminuam o preconceito e os estereótipos negativos acerca da adoção homoparental. 
Entende-se que a coleta de dados, por si só, foi uma intervenção social, que permitiu 589 pessoas adultas de diferentes regiões brasileiras refletirem acerca do tema em questão e certamente, discutir sobre o mesmo com outras pessoas. O processo científico é fundamental para cooperar na mudança das representações sociais e atitudes da população, afinal a prática das ciências sociais leva à fundamentação das suas concepções cotidianas (as representações sociais).

$\mathrm{O}$ fato de ser online, fez com que a maioria dos participantes tivessem alto grau de escolaridade, sendo em sua maioria, com ensino superior incompleto, o que provavelmente ocasionou na aceitação por maior parte da amostra. Porém, estudos da década anterior mostram desfavorabilidade mesmo entre universitários (Araújo \& Oliveira, 2008; Araújo et al., 2007), já pesquisas do início da década atual registram redução quanto ao níveis de preconceitos (Costa et al., 2013; Pereira et al., 2013). A escolaridade contribui com a positividade, mas a evidência de que a sociedade está se moldando vai além deste viés amostral.

Das limitações desse estudo, tem-se certa dificuldade no recrutamento dos participantes, mesmo sendo online, houve bastante recusa, demonstrando um obstáculo que as pessoas têm em falar sobre temas ditos "polêmicos" para a sociedade. Além disso, pode-se ter o efeito de desejabilidade social, quando se verifica a tendência de positividade nas representações sociais sobre adoção e o desenvolvimento infantil por homosexuais. Por fim, cita-se o número reduzido de pesquisas sobre o tema, principalmente no contexto brasileiro, o que dificulta a discussão dos resultados desse estudo.

A despeito das limitações, sugere-se que esta investigação sirva como escopo, nas capacitações profissionais, graduações e palestras, para gerar novas discussões e reflexões a respeito da adoção e desenvolvimento infantil no contexto homoparental, podendo fomentar e executar políticas públicas que efetivem o direito de constituir família para casais formados por pares do mesmo sexo. Sugere-se que novos estudos considerem amostras mais específicas, como pessoas com menos acesso à informação, profissionais da educação e outros, nos diversos contextos do mundo, podendo englobar, ainda mais, diferentes pensamentos em futuras investigações.

\section{Referências}

Almeida, M. (2008). A adoção por homens que tem sexo com homens: Um caminho para o exercício da parentalidade. In Conselho Federal de Psicologia, Adoção: Um direito de todos e todas (pp. 27-30). Brasília, DF: Autor.

Araújo, L. F., \& Oliveira, J. S. C. (2008). A adoção de crianças no contexto da homoparentalidade. $\mathrm{Ar}$ quivos Brasileiros de Psicologia, 60(3), 40-51.

Araújo, L. F., Oliveira, J. S. C., Sousa, V. C., \& Castanha, A. R. (2007). Adoção de crianças por casais homoafetivos: Um estudo comparativo entre universitários de Direito e de Psicologia. Psicologia \& Sociedade, 19(2), 95-102.

Arruda, Â. (2002). Teoria das representações sociais e teorias de gênero. Cadernos de Pesquisa, 117(127), 127-147.

Baiocco, R., Argalia, M., \& Laghi, F. (2014). The desire to marry and attitudes toward samesex family legalization in a sample of Italian lesbians and gay men. Journal of Family Issues, 35(2), 181-200. doi:https://dx.doi. org/10.1177/0192513X12464872

Baiocco, R., \& Laghi, F. (2013). Sexual orientation and the desires and intentions to become parents. Journal of Family Studies, 19(1), 90-98. doi:https://dx.doi.org/10.5172/jfs.2013.19.1.90

Barroso, L. R. (2011). Diferentes, mas iguais: O reconhecimento jurídico das relações homoafetivas no Brasil. Revista Brasileira de Direito Constitucional, 17(1), 105-138.

Bergman, K., Rubio, R. J., Green, R. J., \& Padròn, E. (2010). Gay man who become fathers via surrogacy: The transition to parenthood. Journal of GLBT Family Studies, 6, 111-141. doi:https:// dx.doi.org/10.1080/15504281003704942

Camargo, B. V., \& Justo, A. M. (2013). IRAMUTEQ: Um software gratuito para análise de dados textuais. Temas em Psicologia, 21, 513-518. doi:http://dx.doi.org/10.9788/TP2013.2-16

Cecílio, M. S., Scorsolini-Comin, F., \& Santos, M. A. (2013). Produção científica sobre adoção por casais homossexuais no contexto brasileiro. Estudos de Psicologia (Natal), 18, 507- 
$516 . \quad$ doi:http://dx.doi.org/10.1590/S1413$-294 X 2013000300011$

Cerqueira-Santos, E., \& Santana, G. (2015). Adoção homoparental e preconceito: Crenças de estudantes de Direito e Serviço Social. Temas em Psicologia, 23(4), 873-885. doi:https://dx.doi. org/10.9788/TP2015.4-06

Conselho Nacional de Justiça. (2015). Processos relacionados à adoção no Brasil: Uma análise sobre os impactos da atuação do Poder Judiciário. Brasília, DF: Autor.

Costa, P. A., Caldeira, S., Fernandes, I., Rita, C., Pereira, H., \& Leal, I. (2013). Atitudes da população portuguesa em relação à homoparentalidade. Psicologia: Reflexão e Crítica, 26(4), 790-798. doi:http://dx.doi.org/10.1590/S010279722013000400020

Delacruz, A. M. A., \& Uziel, A. P. (2014). Transformações sociais e culturais da família: Considerações iniciais a partir de um caso. Revista Conexões Psi, 2, 57-83.

Dias, J. R. D. L. (2011). Percursos da racionalização do sagrado no espiritismo: Um conjunto de ideias presentes na literatura e na imprensa brasileira (Tese de doutorado, Pontifícia Universidade Católica do Rio Grande do Sul, Porto Alegre, RS, Brasil).

Dias, M. B., \& Reinheimer, T. L. (2013). Homoparentalidade: Uma realidade. In C. J. Cordeiro \& J. A. Gomes (Eds.), Temas contemporâneos de direito das famílias (pp. 6-503). São Paulo, SP: Pillares.

Fiuza, M. (2015, 20 março). Pela primeira vez, STF reconhece direito de adoção por casais homossexuais. Jusbrasil Recuperado em http://moemafiuza.jusbrasil.com.br/noticias/175556906/ pela-primeira-vez-stf-reconhece-direito-de-adocao-por-casais-homossexuais?ref=topic_feed

Freires, L. A. (2015). Atitudes frente a homoparentalidade: Uma explicação a partir de variáveis explícitas e implícitas (Tese de doutorado, Universidade Federal da Paraíba, João Pessoa, PB, Brasil).

Frias-Navarro, D., Monterde-i-Bort, H., Barrientos-Delgado, J., Badenes-Ribera, L., \& Cardenas-Castro, M. (2014). Beliefs about children's adjustment in same-sex families: Spanish and Chilean university students. The Spanish Journal of Psychology, 17, E5. doi:http://dx.doi. org/10.1017/sjp.2014.5
Gato, J., \& Fontaine, A. M. (2010). Desconstruindo preconceitos sobre a homoparentalidade. LES Online, 2(2), 14-21.

Grossi, M. P. (2003). Gênero e parentesco: Famílias gays e lésbicas no Brasil. Cadernos Pagu, 21, 261-280.

Instituto Brasileiro de Geografia e Estatística. (2011). Censo Demográfico 2010. Rio de Janeiro, RJ: Autor.

Jodelet, D. (2001). As representações sociais. Rio de Janeiro, RJ: Editora da Universidade do Estado do Rio de Janeiro.

Lei $\mathrm{N}^{\mathrm{o}}$ 12.010, de 3 de agosto de 2009. (2009, 02 set.). Diário Oficial da União. Recuperado em http://www.planalto.gov.br/ccivil_03/_ato20072010/2009/lei/112010.htm

Lei $\mathrm{N}^{\circ}$ 8.069, 13 de Julho de 1990. (2014). Estatuto da Criança do Adolescente. Recuperado em http:/www.conselhodacrianca.al.gov.br/sala-de-imprensa/publicacoes/ECA\%20ATUALIZADO.pdf/view

Machin, R. (2016). Homoparentalidade e adoção: (RE) Afirmando o seu lugar como família. Psicologia \& Sociedade, 28(2), 350-359. doi:https:// dx.doi.org/10.1590/1807-03102016v28n2p350

Moscovici, S. (2003). Representações Sociais: Investigações em Psicologia Social. Petrópolis, RJ: Vozes.

Murphy, D. A. (2013). The desire for parenthood: Gay men choosing to become parents through surrogacy. Journal of Family Issues, 34, 1104-1124. doi:http://dx.doi. org/10.1177/0192513X13484272

Nascimento, A. R. A., \& Menandro, P. R. M. (2006). Análise lexical e análise de conteúdo: Uma proposta de utilização conjugada. Estudos e Pesquisas em Psicologia, 6(2), 1-17.

Pacilli, M. G., Taurino, A., Jost, J. T., \& van der Toorn, J. (2011). System justification, right-wing conservatism, and internalized homophobia: Gay and lesbian attitudes toward same-sex parenting in Italy. Sex Roles, 65(7-8), 580-595. doi:http:// dx.doi.org/10.1007/s11199-011-9969-5

Passos, M. C. (2005). Homoparentalidade: Uma entre outras formas de ser família. Psicologia Clínica, 17(2), 31-40.

Patterson, C. J. (2006). Children of lesbian and gay parents. Current Directions in Psychological Science, 15(5), 241-244. 
Pereira, A., Monteiro, M. B., \& Camino, L. (2009). Social norms and prejudice against homosexuals. The Spanish Journal of Psychology, 12, 576-584. doi:http://dx.doi.org/10.1017/ S1 138741600001943

Pereira, C. R., Torres, A. R. R., Falcão, L., \& Pereira, A. S. (2013). O papel de representações sociais sobre a natureza da homossexualidade na oposição ao casamento civil e à adoção por famílias homoafetivas. Psicologia: Teoria e Pesquisa, 29(1), 79-89. doi:http://dx.doi.org/10.1590/ S0102-37722013000100010

R Development Core Team. (2011). R: A language and environment for statistical computing. Vienna, Austria: R Foundation for Statistical Computing.

Ratinaud, P. (2009). IRAMUTEQ: Interface de R pour les Analyses Multidimensionnelles de Textes et de Questionnaires [Computer software]. Retrieved from http://www.iramuteq.org

Reinert, M. (1990). Alceste: une methologie d'analyse dês donnees textualles et une application. Bulletin de Méthodologie Sociologique (Paris), 28, 24-54.

Resolução 175, de 14 de maio de 2013. (2013). Enunciado Administrativo $N^{o} 14$, de 14 de maio de 2013. Brasília, DF: Conselho Nacional de Justiça. Recuperado em http:/www.cnj.jus.br/images/ imprensa/resolu\%C3\%A7\%C3\%A3o_n_175. pdf

Silva, D. A., \& Uziel, A. P. (2011). Esta é uma casa de família! A homoparentalidade sob o olhar de duas diferentes gerações. In Anais II Seminário Internacional Enlaçando Sexualidades. Sal- vador, BA: Universidade do Estado da Bahia. Recuperado em https://nugsexdiadorim.files. wordpress.com/2011/12/esta-c3a9-uma-casa-de-famc3adlia-a-homoparentalidade-sob-o-olhar-de-duas-diferentes-gerac3a7c3b5es.pdf

Silva, M. P., \& Silveira, F. C. (2015). Adoção Homoafetiva à luz do princípio da dignidade da pessoa humana. Judicare, 7(1), 32-49. Recuperado em http://ienomat.com.br/revistas/index.php/judicare/article/view/130

Uziel, A. P. (2007). Homossexualidade e adoção. Rio de Janeiro, RJ: Garamond.

Xavier, P., Mendes, F., Martins, E., \& Fernandes, R. (2011). A homoparentalidade na perspectiva de estudantes do Ensino Superior. In Actas do XI Congreso Internacional Galego-Portugués de Psicopedagoxía. Revista Galego-Portuguesa de Psicoloxía e Educación.

Zambrano, E. (2006). Parentalidades “impensáveis”: Pais/mães homossexuais, travestis e transexuais. Horizontes Antropológicos, 12, 123-147.

(C) O(s) autor(es), 2018. Acesso aberto. Este artigo está distribuído nos termos da Licença Internacional Creative Commons Atribuição 4.0 (http://creativecommons.org/licenses/by/4.0/), que permite o uso, distribuição e reprodução sem restrições em qualquer meio, desde que você dê crédito apropriado ao(s) autor(es) original(ais) e à fonte, fornecer um link para a licença Creative Commons e indicar se as alterações foram feitas. 